\title{
Analysis of Key Technologies for New Green Marine Propulsion Systems
}

\author{
Zheng Duan ${ }^{a}$, Yajie Chen ${ }^{a^{*}}$, Haibo Gao ${ }^{b}$, Linhao Liao ${ }^{b}$ \\ ${ }^{a}$ The 711st Research Institute of China Shipbuilding Industry Corporation,Shanghai,China \\ bchool of Energy and Power Engineering, Wuhan University of Technology, Wuhan,China
}

\begin{abstract}
The new green Marine propulsion system, as a new generation of marine propulsion, has advantages of strong mobility, low fuel consumption, low noise, safety and comfort. Three green propulsion solutions for different ship types are proposed, including pure electric propulsion system, compound energy storage electric propulsion system and diesel-electric hybrid propulsion system. The structure features and performance advantages are introduced and the key technologies such as new energy storage, DC network and shaft generator/motor are discussed. The related research achievements and typical project cases are also introduced.
\end{abstract}

\section{Introduction}

The performance of the ship's propulsion system has a great influence on economy, safety and reliability of the ship. The traditional mechanical propulsion system has the problems of high noise, small speed range, poor flexibility and economic efficiency, which cannot meet the requirements of marine propulsion development. Therefore, new propulsion system has gradually become a research hotspot in the shipping industry. In recent years, new rules such as the new ship energy efficiency design index and the new ship construction standards issued by the International Maritime Organization, as well as the "CCS Green Ship Code" issued by China Classification Society, have promoted the development theme of "green power" ${ }^{\prime \prime}$.

Hybrid power and new energy have always been the research hotspots of ship green power. Hybrid power and shaft generator/motor technology can optimize system power distribution, thereby reducing system losses and improving system efficiency. Composite energy sources such as storage batteries, super capacitors, fuel cells, and solar and wind energy are matched with energy storage devices and DC grid technology, which can achieve zero emission target and can also recover and store braking energy.

This paper focuses on the theme of green and high efficiency, based on the analysis of the power requirements of different ship types, comprehensively considering the technical conditions of energy supply, ship power distribution, drive control, propulsion, etc., and proposes the three marine green propulsion solutions. The key technologies of green propulsion involve energy storage technology, DC networking technology and shaft generator/motor technology; the technical features are discussed in each solution and the related research and application cases of green ships conducted by the 711st Research Institute of China Shipbuilding Industry Corporation are demonstrated.

\section{Marine Green Power Solutions}

Due to the difference in energy form, power conversion, networking technology and propulsion type, there are many options available for combination; this paper proposed three solutions based on the different needs of different ship types. They are pure electric propulsion system; compound energy storage electric propulsion system and diesel-electric hybrid propulsion plan ${ }^{[2-3]}$.

\subsection{Pure electric propulsion system}

The pure electric solution is aimed at ships that do not depend on air and have high power density requirements, such as underwater vehicles and deep sea mobile stations, and ships that run in high environment standard waters such as rivers and lakes. This solution adopts energy storage batteries, DC power distribution, shaftless rim-driven thrusters. The structural diagram of this solution is shown in Fig. 1. 


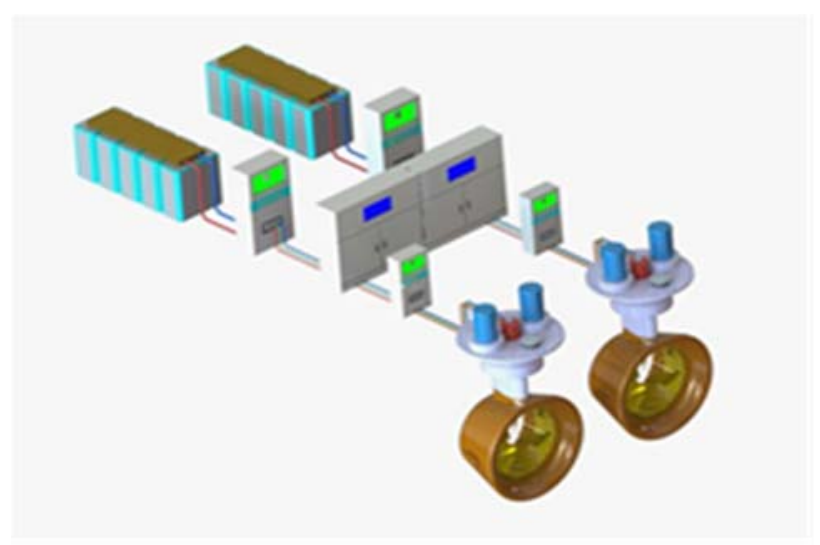

Fig. 1. Pure electric propulsion system

In the scheme of Fig. 1, lithium iron phosphate or ternary lithium battery pack or super capacitor bank is used as the energy source, distributed through the DC bus, to drive the shaftless rim thruster through the inverter to propel the ship. The shaftless rim thruster is shown in Fig. 2.

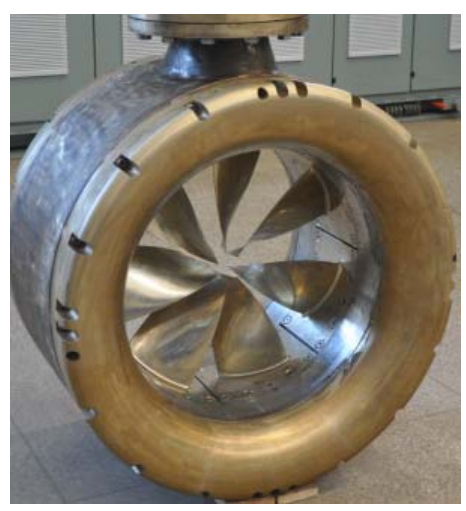

Fig. 2. Shaftless rim thruster

As shown in Fig. 2, the stator of the motor is integrated in the duct, the rotor and the propeller are integrated, and the propeller is changed from an axial connection to a radial connection.

This thruster has the advantages of high efficiency, small vibration noise, small volume, light weight, safety and reliability, and flexible layout.

\subsection{Compound energy storage electric propulsion system}

The composite energy storage electric propulsion system is designed for small and medium-power, fixed-route, and strict emission control ship types such as ferries, inland cruise ships, and some engineering ships. Composite energy, new energy storage devices, DC networking, pod propulsion and other technologies are utilized comprehensively. The scheme structure is shown in Fig. 3.

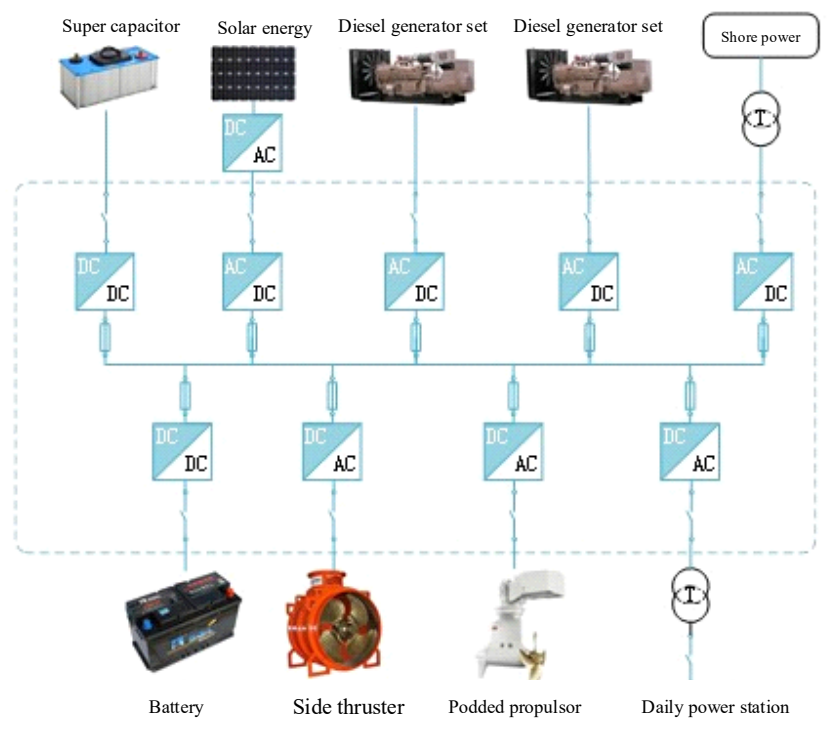

Fig. 3. The scheme of composite energy storage electric propulsion system

In Fig. 3, diesel generator sets + battery packs (or super capacitor) + new energy source are used to form a power supply system, and a battery pack (or super capacitor) forms an electric energy storage device. DC networking technology combined with energy storage technology can reasonably and efficiently distribute and store electric energy by making full use of the advantages of the characteristics of each energy source. The main propeller adopts podded propulsor, which can optimize the ship type and power system layout, and improve the ship's maneuverability and reliability. This solution has the advantages of energy saving and emission reduction, increased redundancy, convenient maintenance and flexible control, and high comfort.

\subsection{Diesel-electric hybrid propulsion system}

The diesel-electric hybrid propulsion system is aimed at ship types with high power demand and variable working conditions, such as engineering ships and scientific research ships. It adopts shaft generator/motor technology, AC power distribution technology and shaft line propulsion technology. The structure of the scheme is shown in Fig. 4. According to the installation position of the shaft motor, the scheme may have two types including coaxial shaft motor and gear shaft motor. 


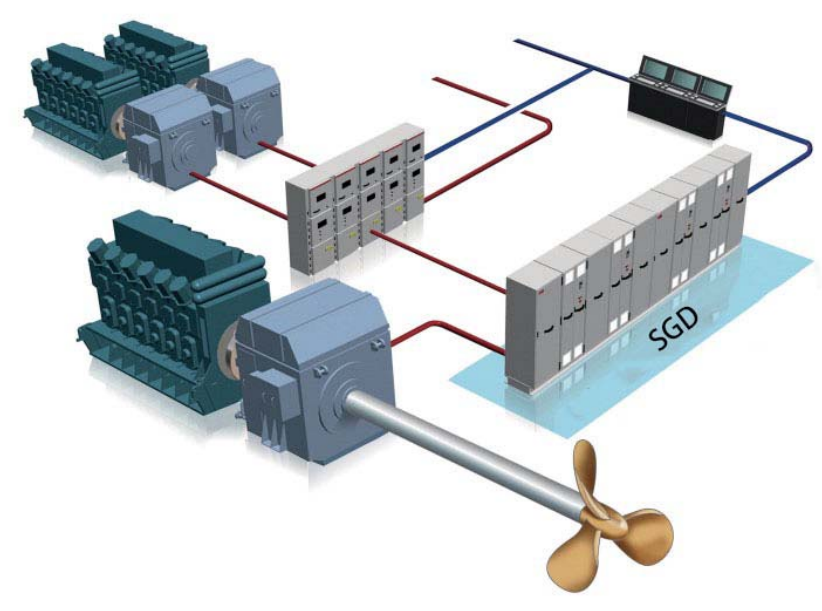

Fig. 4. New diesel-electric hybrid propulsion system

In the hybrid propulsion solution as shown in Fig. 4, the shaft motor can operate as either a generator or an electric motor. In generator mode, the generated unstable $\mathrm{AC}$ power is converted into constant voltage and constant frequency $\mathrm{AC}$ power through the rectification and inversion control, which can achieve a stable power supply within a large range of engine speed. When operating as a motor, it can absorb electric energy from the power station to enhance propulsion power.

\section{Key technologies in green propulsion solutions}

\subsection{Energy storage technology}

Aiming at the power grid's voltage fluctuations caused by frequent load changes, adopting of energy storage technology can improve the power supply quality and optimize the energy flow to meet the requirement of peak demand, when the power demand is low or the cost of electricity consumption is low, excess electric energy can be stored, so as to achieve the purpose of reducing the capacity of the diesel engine, optimizing engines' working state, and improving the system energy efficiency. Among various combinations of energy storage devices, lithium batteries (or super-capacitors) are the most widely used. Lithium battery has high energy density and good steady-state performance. Super-capacitor has high power density and good dynamic performance. Combing lithium battery and super-capacitor, the energy storage system can have both good dynamic characteristics and steady-state characteristics ${ }^{[4]}$. However, energy storage devices still have problems such as low energy storage density, short service life and high initial investment, which limits their wide application on ships ${ }^{[5]}$.

\subsection{DC networking technology}

Unlike the AC networking technology, the DC networking technology is a brand new networking technology. The topology of the electric propulsion system of the AC network and the DC network is shown in Fig 5.

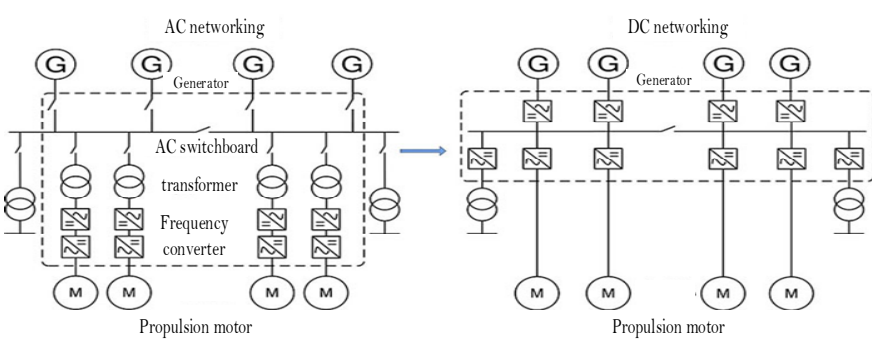

Fig. 5. Scheme structure of the electric propulsion system of AC network and DC network

The DC network system abandons the switchboard and transformer in the $\mathrm{AC}$ network system, it splits the AC-DC-AC conversion in converter, and shifts the networking side from the original AC side to the DC side, which solves the problem of diesel generator grid connection, harmonic suppression and other technical problems.

The DC network system eliminates the need for equipment such as switchboards and transformers. The equipment integration level is high, the system architecture is simple, and the weight and the volume are greatly reduced, the layout of the engine room can be simplified. At the same time, a large number of cables and equipment interfaces are omitted, which reduces the system cost. This scheme reduces the energy conversion link to achieve a higher overall efficiency. Its structure is shown in Fig. 6.

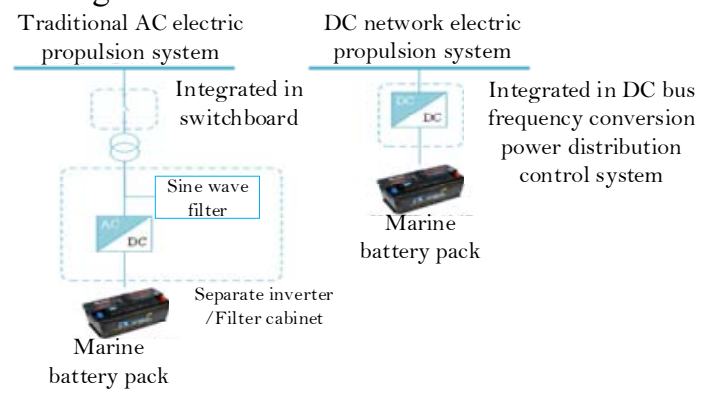

Fig. 6. Use methods for battery packs in AC and DC networking systems

The DC network system has better compatibility than the AC network system, the system configuration is more flexible, and it is easy to adopt energy storage devices such as batteries and new energy sources. In the form of hybrid power composed of diesel engines and energy storage equipment, the energy storage system compensates and absorbs sudden load changes on the power grid, suppresses load fluctuations, and improves the working conditions of the prime mover to achieve energy saving effects. At the same time, the DC networking technology combined with the variable speed diesel engine scheme can make the unit run at the optimal energy consumption point, reduce emissions, and achieve energy-saving operation in the full power range.

The 711st Research Institute has designed DC network electric propulsion system for a number of ships, among which the hybrid DC network system composed of energy storage equipment and variable speed units has 
applied 7 ferries, and the actual ship has achieved over 13\% fuel saving effect, which has been recognized by ship owners and classification societies.

At present, the mainstream DC network electric propulsion system scheme adopts the synchronous generator set + Diode Front End (DFE) rectification mode, as shown in Fig. 7 (a).

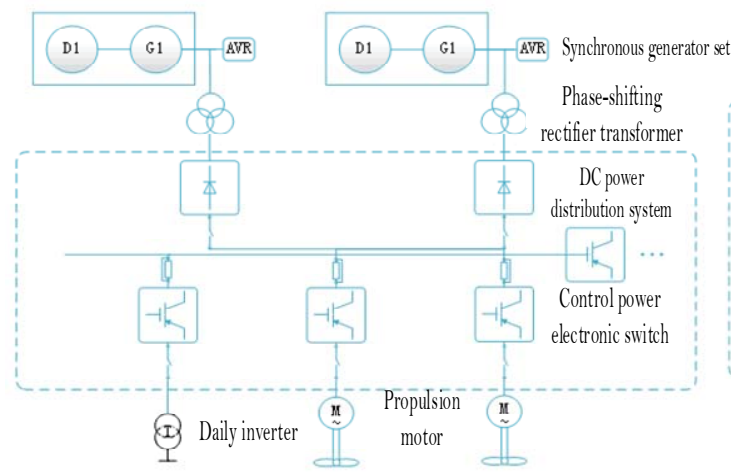

(a) DFE rectification networking solution

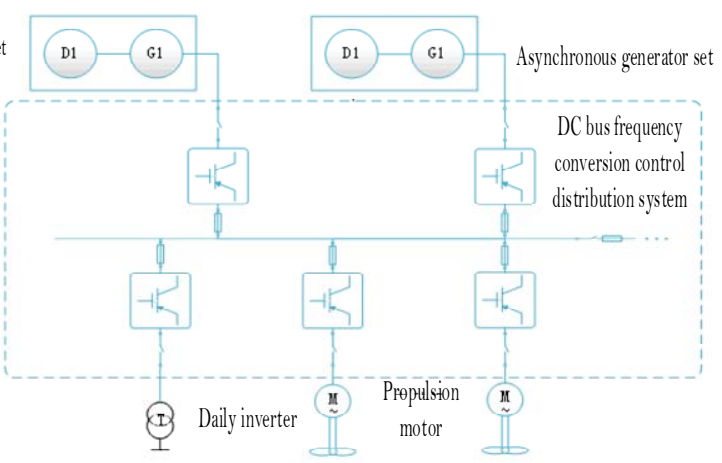

(b) AFE rectification networking solution

Fig. 7. AFE rectification and DFE rectification networking solution

The power device used in the DFE front rectifier is diode. Due to uncontrollable diodes, a large amount of low-order and high-order harmonics is generated to inject into network side. Generally, 12-pulse or 24-pulse rectification is designed with phase-shifting rectifier transformer to reduce harmonics on the ship's power grid.

The reformed DC network electric propulsion system scheme is shown in Fig. 7 (b). It introduces the German E-MS technology and adopts the asynchronous generator set + Active Front End (AFE) rectification technology. AFE front-end using Insulated Gate Bipolar Transistor (IGBT), by controlling the on-off of IGBT, can improve system power factor, reduce the harmonic effect, and keep the DC bus voltage stable. The unit is connected to the grid on the DC side through an independent frequency conversion module, and control system, eliminating the need for phase-shifting rectifier transformers, and has a smaller weight and volume. It is suitable for applications with demand for low harmonic of the main power supply [7].

As shown in Table 1, asynchronous motor +AFE rectification scheme is adopted to make the system grid more stable. The failure of the generator will not lead to voltage and current fluctuation of the bus, and there is no risk of grid collapse. The method of grid connection is simpler, the process of grid connection is easier, and the response ability of the diesel is stronger.

Table 1. Comparison of grid connection process of AFE rectification scheme and DFE rectification scheme

\begin{tabular}{|c|c|c|}
\hline main & AFE Rectification & DFE \\
feature & Network Solution & $\begin{array}{c}\text { rectification } \\
\text { networking } \\
\text { solution }\end{array}$ \\
\hline
\end{tabular}

\begin{tabular}{|c|c|c|}
\hline $\begin{array}{c}\text { Grid } \\
\text { connection } \\
\text { mode }\end{array}$ & $\begin{array}{c}\text { Independent grid } \\
\text { connection, no } \\
\text { mutual influence } \\
\text { between units }\end{array}$ & $\begin{array}{c}\text { Coordinated grid } \\
\text { connection, } \\
\text { grid-connected } \\
\text { units need to be } \\
\text { synchronized } \\
\text { and connected }\end{array}$ \\
\hline $\begin{array}{c}\text { Grid } \\
\text { connection } \\
\text { time }\end{array}$ & $\begin{array}{c}\text { After the diesel } \\
\text { engine started } \\
\text { successfully, the } \\
\text { grid connection time } \\
\text { is } 0.5 \mathrm{~s}\end{array}$ & $\begin{array}{c}\text { After the diesel } \\
\text { engine started } \\
\text { successfully, the } \\
\text { grid connection } \\
\text { time is more } \\
\text { than } 10 \mathrm{~s}\end{array}$ \\
\hline $\begin{array}{c}\text { Power grid } \\
\text { voltage } \\
\text { fluctuation }\end{array}$ & $\leq 2 \%$ & $\geq 5 \%$ \\
\hline
\end{tabular}

\subsection{Modern shaft generator/motor technology}

The modern shaft motor system can upgrade the traditional shaft motor system through the shaft generator/motor inverter. The main functions of the shaft generator/motor inverter are to control the shaft generator for fast and flexible grid connection, and provide electric energy to the load. It is mainly composed of control winding side inverter, grid side filter, grid side inverter, input reactor, output reactor, control system and related grid-connected switch ${ }^{[8]}$.

The structure of the modern shaft generator/motor system is shown in Fig. 8. According to its installation location, the modern shaft generator/motor system can be divided into two types: coaxial mode and gear mode. The converter is connected to the ship power grid and automation system, and the operation mode of shaft generator/motor can be controlled automatically by converter ${ }^{[9-10]}$. 


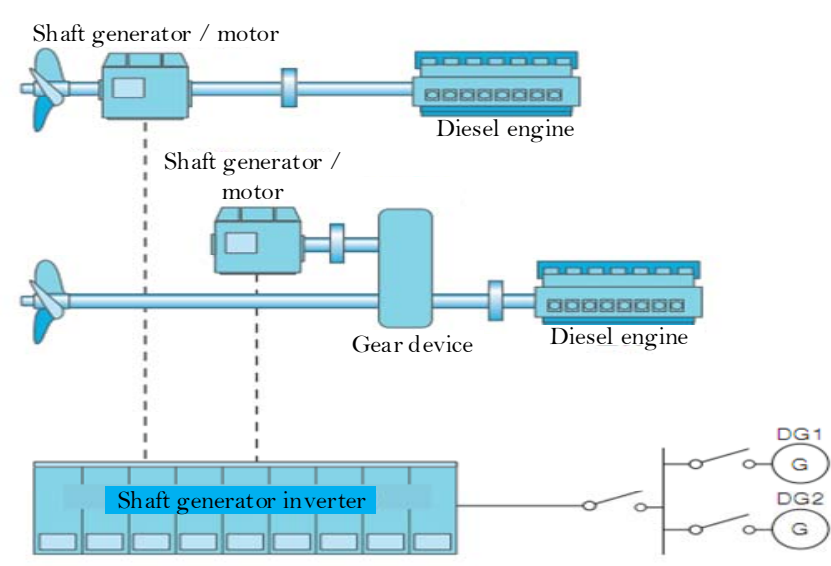

Fig. 8. Installation method of modern shaft motor

The modern shaft generator/motor system has three operating modes, namely Power Take Out (PTO) mode, Power Take In (PTI) mode and shore-to-ship mode. The three modes of operation are shown in Figure 9.

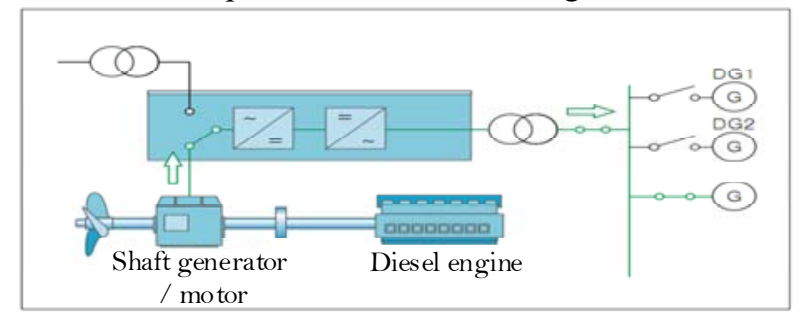

PTO mode:Energy flow from shaft generator to marine power grid

(a) PTO mode

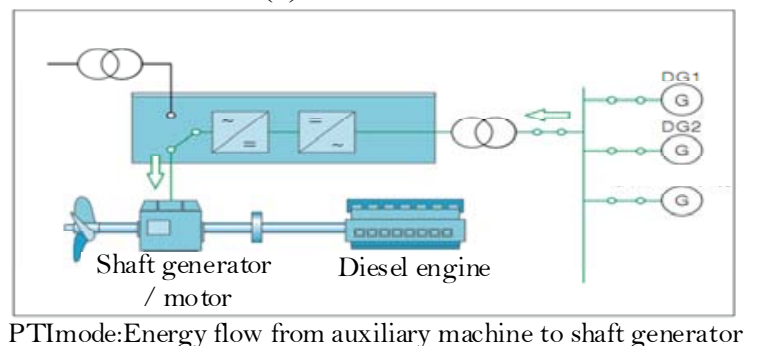

(b) PTI mode

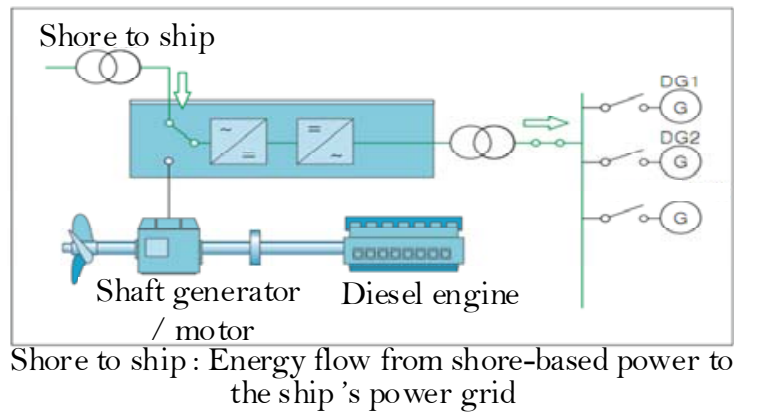

(c) Shore-to-ship mode

Fig. 9. Mode of operation of a modern shaft motor system

As shown in Fig. 9 (a), in the PTO mode, the shaft generator/motor operates as a generator. The converter can run in island mode, which means the shaft generator supplies power to other loads alone, it can also operate in parallel with other generator sets. At this time, the inverter can adopt droop control to adjust the voltage and frequency to achieve grid connection with other generator sets.

As shown in Fig. 9 (b), in the PTI mode, the shaft generator/motor operates as a motor, which is powered by the diesel generator, the converter is responsible for controlling the motor. When the main engine fails, the safe return mode can be activated. After disconnecting the main engine from the shaft line, the shaft motor runs independently to drive the propeller. When the shaft motor is running normally, it can boost the main engine. At this time, the shaft motor is adjusted by a converter to keep it running synchronously with main engine.

As shown in Fig. 9(c), in the shore-to-ship mode, the cnverter provides a flexible solution for onshore power grid connection, supporting $50 \mathrm{~Hz}$ or $60 \mathrm{~Hz}$ power grids and a variety of voltage levels. The switch between diesel generator set and shore power is seamless. The diesel generator can keep running when the shore power is connected to the converter. After the converter is synchronized with the diesel generator set, the diesel generator can be shut down. At this time, the power required on board will be provided by the shore power.

In summary, the modern shaft generator/motor technology can optimize the working condition of the main engine through the converter to achieve the effect of energy saving and emission reduction. When the main engine fails, the ship can be powered by the shaft motor to increase the power redundancy and improve the safety of the ship. By a variety of operating modes, it increases the flexibility of ship operation; it also can connect the shore power of different voltage levels to the ship's power grid.

\section{Research achievements application cases of green ships}

and

Green ship is a great reform of shipping industry, which has promoted the development of many advanced technologies, Domestic and foreign companies are actively exploring and have achieved certain results. This section mainly introduces the related research results and application cases of Siemens, Danfoss and the 711 research institute.

\subsection{Achievements in scientific research}

Danfoss has proposed a solution for the M/V Bore Sea large ro-ro ship that will fully optimize the main propulsion and further improve the ship's energy efficiency. The VACON NXP type grid-connected inverter and shaft motor was selected for propulsion system, which can allow the engine speed to vary greatly, and can provide a stable voltage and frequency alternating current. By optimizing the efficiency of the engine, it can maximally reduce fuel consumption.

Siemens has proposed an innovative sustainable solution, the Blue drive Plus $\mathrm{C}$ system for ship propulsion. Which contains the DC grid, economical electric propulsion system, electric power booster system, integrated monitoring alarm and control system. Siemens 
also developed the marine energy optimization management system, and obtained the ship fuel consumption, emissions, fuel refueling, maintenance period and other operational data, through the evaluation and analysis of these data to achieve the optimization of ship operations.

In 2016, the 711st Research Institute of China Shipbuilding Industry Corporation set up a DC network electric propulsion system laboratory with complete independent intellectual property rights (See Fig. 10), and carried out research and verification of several key technologies such as energy storage technology, variable speed control of diesel generator sets, DC micro-grid distribution technology, DC distribution relay protection technology, and so on. A series of experiments can be carried out in the laboratory, such as the energy saving strategy of variable speed generator sets, the security protection strategy of DC power grid and the energy management strategy. The 711st Research Institute also realized the complete independent development of inverter, DC distribution cabinet and energy storage control system. Several technical bottlenecks have been broken, which includes:

1)DC power distribution and energy management technology.

2) DC power distribution system's protection technology.

3) Battery's BMS management technology.

4) variable speed control for generator set.

5) constant frequency technology for variable speed of shaft generator

Based on the above technologies, pure electric propulsion system, composite energy storage electric propulsion system and diesel-electric hybrid propulsion power system can be realized.

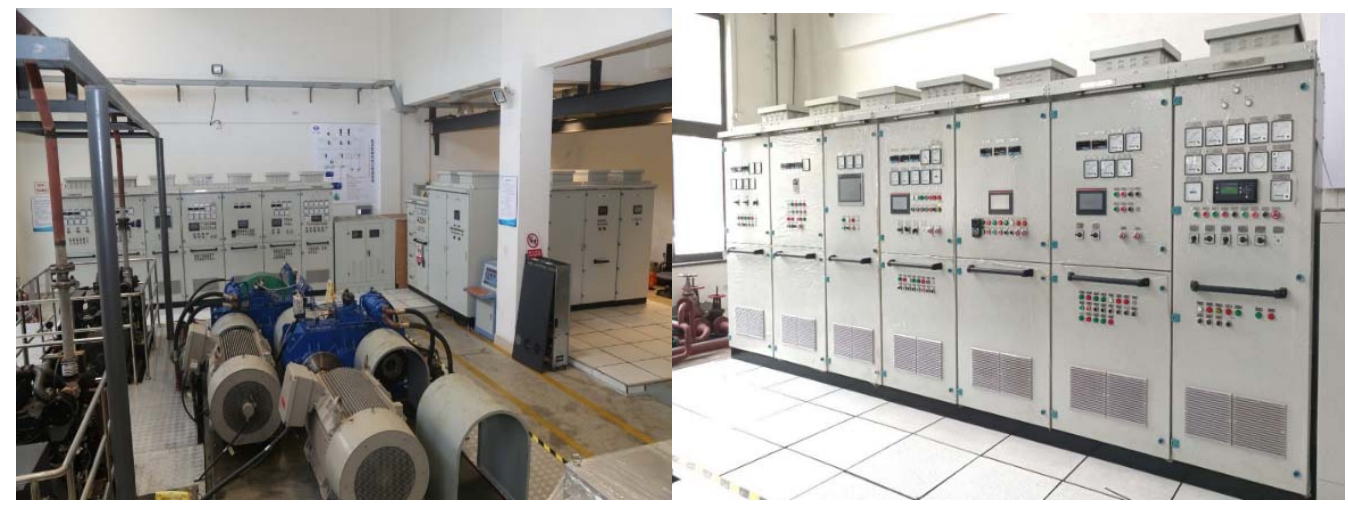

Fig. 10. DC network electric propulsion laboratory

\subsection{Application Cases}

At present, the 711st Research Institute has the design and integration experience of nearly 10 ships' DC distribution electric propulsion systems, covering the three proposed solutions.

(1) Electric power propulsion system

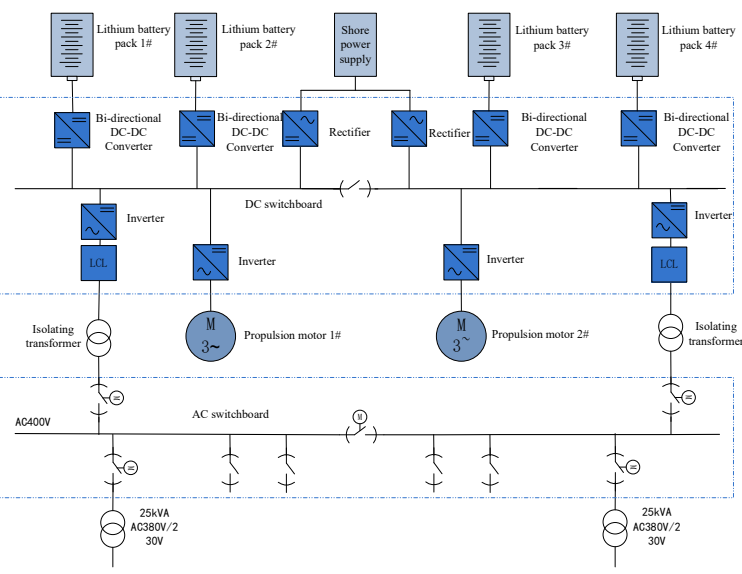

Fig. 11. Single line drawing of pure electric propulsion system

"Miyun" water quality monitoring ship was launched in 2019 (see Fig.12). The ship is equipped with a 960kwh battery package as energy source. It's the first time to adopt the lightweight electric propulsion equipment in China. The inverter module weight is only half of the regular modules. The ship is equipped with 2 sets of $100 \mathrm{kw}$ Synchronous Reluctance Assisted Permanent Motor, which weight is only half of the conventional motor, but the propulsive efficiency is as high as $98 \%$, more than $3.1 \%$ higher than jacket cooling motor, what is more, the motor has high torque output characteristics. The power battery package can operate at a stable ambient temperature of $-15^{\circ} \mathrm{C} \sim 45^{\circ} \mathrm{C}$ without external heating. It can ensure the normal operation of the ship in winter, and has an endurance of 8 hours (propulsion power is not full power). 


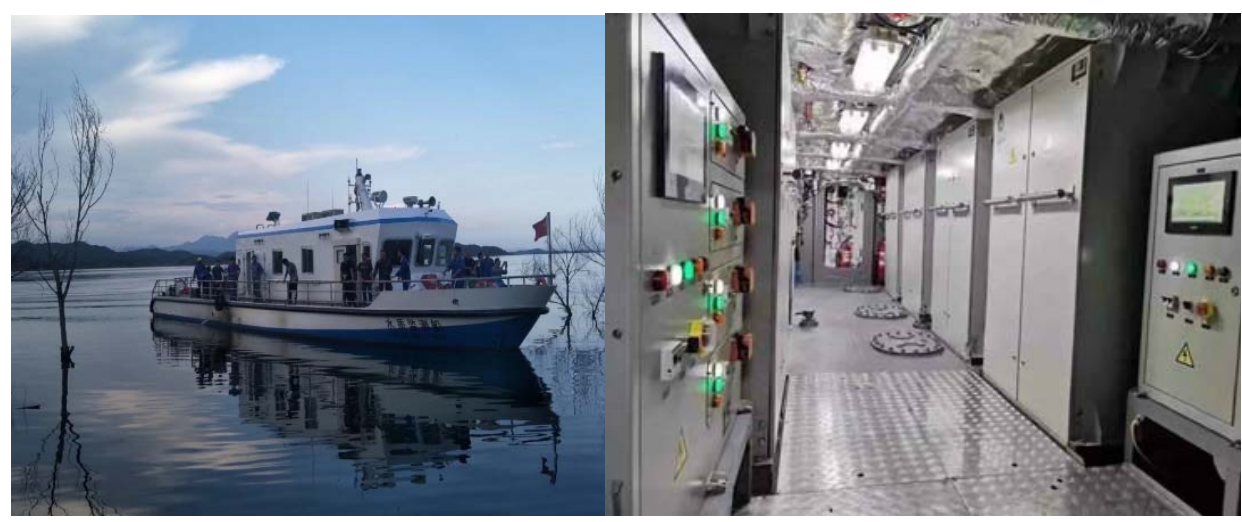

Fig. 12. "Miyun" water quality monitoring ship

(2) composite energy storage electric propulsion system

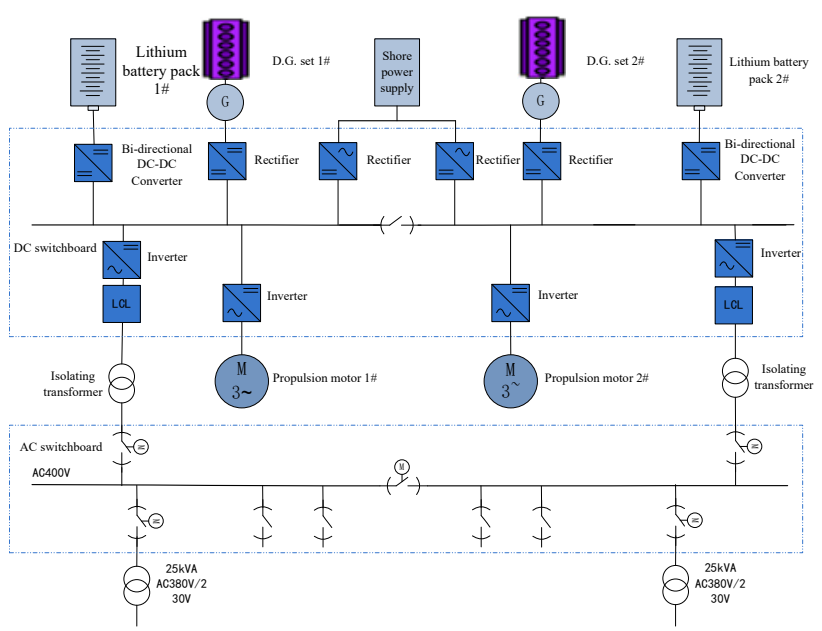

Fig. 13. Single line drawing of composite energy storage electric propulsion system

The 711st research institute applies the composite energy storage electric propulsion system to four "zhenyang" ferries. The system consists of 2 sets of $380 \mathrm{~kW}$ variable speed generator sets (speed range $820 \sim 1800 \mathrm{r} / \mathrm{min}$ ), DC switchboard, 19kwh super-capacitor bank, 2 sets of $350 \mathrm{~kW}$ propulsion motor, power management system and propulsion control system. It breaks through variable speed diesel-asynchronous generator technology and hybrid energy storage technology, and realizes DC grid-connecting technology based on droop characteristics and DC system protection technology. "Jiangsu ferry 3011 " is one of the ships which adopted the above technologies and already in operation as shown in Fig. 14. According to the operating data, the ship has achieved over $12 \%$ oil saving effect and got significant investment benefit, and reduced NOx, SOx, PM and other pollutant emissions.

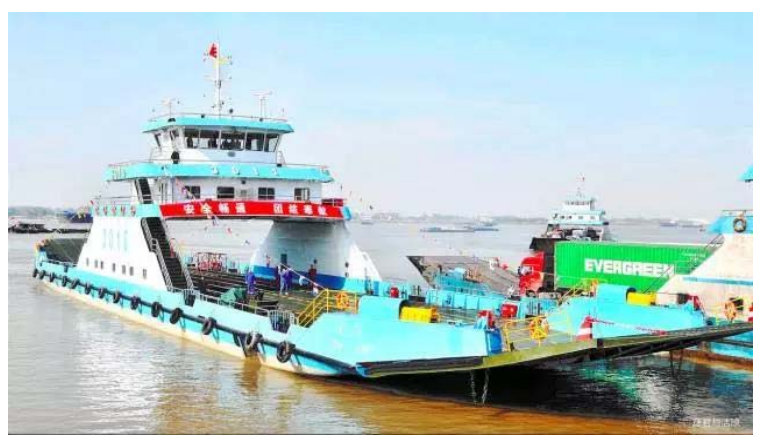

Fig. 14. "Jiangsu ferry 3011 "

(3) Diesel-electric hybrid propulsion system

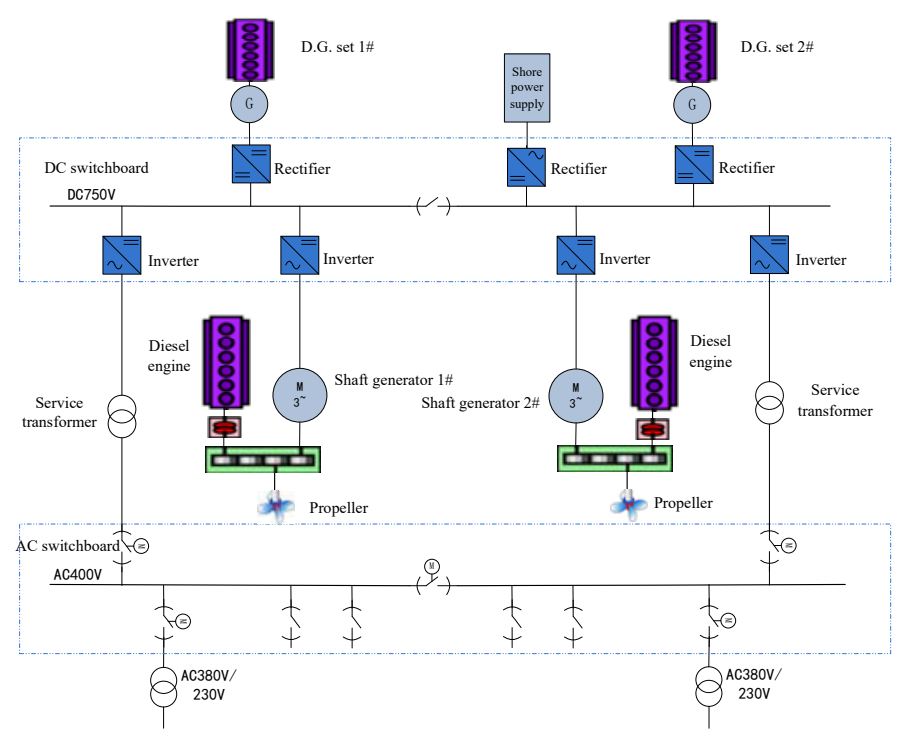

Fig. 15. Single line drawing of diesel-electric hybrid propulsion system

China's first diesel-electric hybrid research vessel Zhejiang ocean university's "zhejiang fishery science 2" fishery resources research vessel, which successfully passed the sea trial in Daishan area of zhejiang province on May 9, 2017, and it is independently designed and integrated by the $711 \mathrm{st}$ research institute. The diesel-electric hybrid research vessel ship is the first domestically developed and designed, which is a comprehensive platform integrating teaching, scientific research, practice and training, and it can meet the needs 
of coastal and offshore exploration. It has three types of propulsion: diesel propulsion, electric propulsion and diesel-electric propulsion.

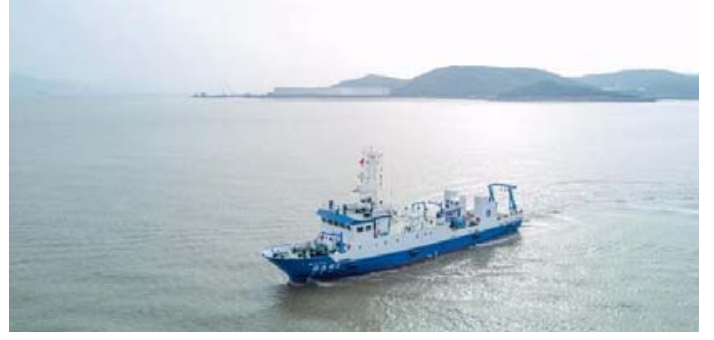

Fig. 16. "Zhejiang fishery science 2"

\section{Conclusion}

This paper proposes three green power solutions, focusing on the key technologies, and briefly introduces the research achievements and engineering applications of relevant enterprises. The actual operation data of the ship shows that the green power solution can not only save energy and reduce emissions, but also have certain advantages in terms of volume and weight, engine room layout and power grid stability. Authors of this paper believe that in the near future, green power solutions will be more widely used.

\section{Acknowledgements}

The authors gratefully acknowledge the financial support provided by Fund of Shanghai Science and technology Commission (19DZ1203100), Fund of Ministry of Science and Technology of China (2018YFB1601500), Fund of National Engineering Research Center for Water Transport Safety(A2019002), NSFC-Zhejiang Joint Fund for the Integration of Industrialization and Informatization (U1709215).

\section{References}

1. Jun Wang. Green ship concept and development trend. East China Science \& Technology, 2013 (2): 423-423.
2. Bo Li. Design and optimization of green tug hybrid power system. Wuhan: Wuhan university of technology, 2015.

3. KJ Lee, D Shin, DW Yoo, et al. Hybrid photovoltaic/diesel green ship operating in standalone and grid-connected mode - Experimental investigation. Energy, 2013, 49(49): 475:483.

4. Cheng Chen, Xihuai Wang, Jianmei Xiao. Application of Energy Storage Devices in Ship Electric Propulsion System. Navigation of China, 2014, 37(4): 25-29.

5. Tianhao Tang, Zhaozhen Han. Ship electric propulsion system. Beijing: machinery industry press, 2015: 339-342.

6. Shuo Xu, Xiang Yun. Comparison of different solutions of onboard DC grid. Ship Science and Technology. 2016, 38(13): 60-63.

7. Zhiqiang Zhang, Jikun Ma, Zhixiang Lu. Review on the Integrated Electric Propulsion System for Fishing Survey Boats. Marine Electric \& Electronic Engineering, 2015, 35 (8): 70-75.

8. Bohwa Lee, Poomin Park, Chuntaek Kim, et al. Power Managements of A Hybrid Electric Propulsion System for UAVs. Journal of Mechanical Science and Technology, 2012, 26(8): 2291-2299.

9. Fredrik Hansen, John O Lindtjorn, Klaus Vanska. Onboard DC Grid for enhanced DP operation in ships. Dynamic Positioning Conference, Jan Fredrik Hansen: Norway, John O Lindtjorn, 2011:1-8.

10. N Xiao, R Zhou, X Xu, et al. Study on Vibration of Marine Diesel-Electric Hybrid Propulsion System. Mathematical Problems in Engineering, 2016, 2016(4): 1-9. 